\title{
Application of Vygotsky's Social Development Theory
}

\author{
Seth Barnett \\ College of Business, Johnson \& Wales University, 8 Abbott Park Place, Providence, RI 02903 \\ E-mail of the corresponding author: info@sethbarnett.com
}

\begin{abstract}
This paper evaluates the application of Vygotsky's Social Development Theory which states that children gain knowledge, at least complex thought, from social interactions with adults and wiser children. It also completes Vygotsky's theory. It is necessary to review this theory at this point in time to help continue to fulfil the needs of adaptive learning for parents and educators. The significance is that even after decades of existence and study, Vygotsky's theory remains an important review in the areas of social development especially in youths. An application of this theory will allow for more effective classroom management, an increased focus on social learning abilities, and will give educators a method of process review in the area of social development. In examination of this theory, classroom management, assessment, lesson preparation, and potential discipline techniques will be discussed. In this, cognitive development theories are principles that focus on a child's activities toward their environment and the process of thought, reason, and memory that result (Huitt \& Hummel, 2003). This theory is especially important to pre-secondary and secondary educators. If an educator attempts to teach at a level that is beneath the students' attainment level, per the theory, they will become bored and less motivated. The other side of the spectrum is a classroom that challenges the students above their level of capability which can also have adverse effects.
\end{abstract}

Keywords: Vygotsky's Theory, Developmental Education, Classroom Management, Developmental Cognition DOI: $10.7176 / \mathrm{JEP} / 10-35-01$

Publication date: December $31^{\text {st }} 2019$

\section{Introduction}

Cognitive developmental theories are principles that focus on a child's activities toward his environment and the processing of thought, reason, and memory that result. One of the major contributors to this philosophy was Russian psychologist Lev S. Vygotsky. His theory has proven to be useful because it includes many testable components. There also lacks adequate evidence to confirm or deny the majority of his ideas. His theory encompasses the ideals of nature and nurture in four stages. In examination of this theory, classroom management, assessment, lesson preparation, and potential discipline techniques will be discussed.

Vygotsky's theory states that children gain knowledge, at least complex thought, from social interactions with adults and wiser children. This theory does not imply that it is impossible for children to learn individually. It merely states that pivotal knowledge and development is gained in a group setting. The more knowledgeable party scaffolds information for the receiving student. This is done by creating the learning experience or collaboration. It is not defined as a teacher conveying knowledge verbally, but more of an interaction that creates discovery for the student (Bee \& Boyd, 2007).

As a child gains knowledge, there is a limit to what he is capable of learning alone. Guidance makes more tasks possible, and the child is then able to attempt harder tasks. This is known as the zone of proximal development. As the student becomes wiser, the zone or range of abilities increases. The first stage of Vygotsky's theory is the primitive stage. This is the stage everyone is born into. Mental processes are rudimentary, and learning is conditional. The naïve psychology stage follows at age 2. During this stage language develops. However, it is not until the egocentric speech stage that a child understands each representation of language and begins to use it to solve problems. This stage takes place around the transition from age 3 to 4 . By the time a child is seven, he internalizes all egocentric speech and uses it throughout adulthood. This stage is the ingrowth stage. It also completes Vygotsky's theory. It lacks definition of development through adolescence and adulthood (Bee \& Boyd, 2007).

Vygotsky's theories are ever-present in an effective classroom. If an educator attempts to teach at a level that is beneath the students' attainment level, they will become bored and less motivated. This is a classroom without challenge, where students may be learning minimal information. The other side of the spectrum is a classroom that challenges the students above their level of capability. Students in this classroom will quickly become frustrated and may also lose confidence (Encyclopedia of Special Education, 2006).

\section{Classroom Management}

Having an effective method of teaching coincides with effective classroom management. The idea is to keep the students focused on learning and interacting with the teacher and fellow students. It takes a creative teacher to come up with and utilize various styles of teaching. 
First, the teacher and students should establish honesty and trust to make teaching and learning become effortless. Common ground has to be secured in the classroom where teacher and student discussions will take place. The students should feel comfortable expressing their ideas to their teacher (Cody, K. \& Powell, K. 2009). This will set up a contagious atmosphere and good classroom management.

Vygotsky believes that social interaction is an integral part of learning. He also believed that social constructivism is based on social interactions in the classroom and how that student critically thinks (Cody, K. \& Powell, K. 2009). Vygotsky's social development theory examines four theoretical application areas: the zone of proximal development, scaffolding, cooperative learning, and cultural influence. Understanding the theories and interaction with them helps develop effective classrooms (Cody, K. \& Powell, K. 2009).

Zone of proximal development is a one where learning is developed when a child has help learning a concept in the classroom. A lot of times children learn best in this zone when others are involved (Cody, K. \& Powell, K. 2009). When children are learning from others in the classroom, there is classroom management because of the involvement of several students.

Scaffolding involves students learning from teachers, peers, and adults. In a counting activity a child may skip a number, but if someone is assisting by pointing and counting out loud with the child, they will get it right (Cody, K. \& Powell, K. 2009). This way the student is learning and not just receiving the answer. It involves classroom management because the student is learning and focused through guided expectations set by the teacher.

Cooperative learning is another one of Vygotsky's learning theories. It involves students working with other students one on one. It is similar to a team environment. Students can learn a lot from one another and put their skills and talents together to complete an assignment with equal input. When students master the completion of projects or activities in a group, each individual internalizes that knowledge more effectively (Cody, K. \& Powell, K. 2009).

Cultural influence is another of Vygotsky's lenses that he believes has a significant impact on how learning occurs. He believes teachers should recognize and embrace different ethnic backgrounds. In this, students learn more about themselves and their own style through observation of those less similar to them. Curriculum should only be started once students have gotten comfortable with each other and had a discussion on their backgrounds according to Vygotsky.

There is a connection in all the social constructivism above. Communication is very pertinent to learning and should be based on the same common ground. Language usage in the classroom is very important according to Vygotsky because it enhances learning and precedes knowledge.

An effective teacher is an effective learner. The main focus is to produce an atmosphere where each student will reach his or her full potential. The teacher must be attentive and offer guidance throughout the process. Developing tools that secure social interaction will improve classroom management. Students and teachers will both benefit from this effective learning atmosphere (Cody, K. \& Powell, K. 2009).

\section{Classroom Assessment}

Classroom assessments are a very important aspect of running an effective class. Assessments are used to help gauge the progress that is being made by each student and assists the instructor is determining the efficiency of the teaching techniques that are being utilized (Simpson-Beck, 2011). There are many different development theories that influence the teaching styles of educators and in turn will influence what types of assessments will be most useful for the teacher. Vygotsky's theory of proximal development supports the idea that a child's development is guided by an adult and child has two levels of development (Bee \& Boyd, 2007). A child's zone of actual development is the child's ability to perform a task individually while the zone of proximal development is the child's ability to perform a task with assistance from an adult. To assess the child's zone of actual development it would be necessary to have the child perform the task independently. Once the baseline, or zone of actual development, is determined, the child should be asked to perform the task with assistance from an adult. Once the zone of proximal development is determined, the child's skills and abilities should be continually assessed with less and less assistance provided. As the child begins to master the skill with less assistance, their zone of proximal development widens to include harder tasks. The child can also take the language used by the instructor during the scaffolding and apply it to future tasks.

According to Garrison and Ehringhaus (2017), while there are many different types of assessments, two particular assessment types that can be helpful is the summative assessment and formative assessment. Using both types of assessments for different reasons will provide the most accurate overview of a classroom or individual student. A summative assessment is given to determine at a particular point in time what a student knows and doesn't know. Formative assessment is another useful type of assessment used to gauge the effectiveness of the teaching style based on the student's understanding of the material and the goals of the teacher (Garrison \& Ehringhaus, 2007).

Based on the idea that development is defined both by what a child can do independently and by what a child can do when assisted by an adult or more competent peer is Vygotsky's concept of the zone of proximal 
development. There are two levels in Vygotsky's zone that is important for teachers to know. Where the child is at a given moment as well as where the child is going is what these levels indicate. There are several implications for teaching in the classroom attained from the zone of proximal development. As a teacher, you want the curriculum to be developmentally appropriate. Activities must be planned that encompass not only what children are capable of doing on their own but what they can learn with the help of others.

\section{Discipline Techniques}

Because this theory is based upon social learning, there are many areas where disciplinary issues can arise. As children age, they are more likely to experience the effects of the social peer group. Often this can lead to misbehavior between genders, acting out, and displaying negative stereotypes. Through Vygotsky's processes a child learns in three ways: imitative, instructional and collaborative learning (Kids Development, 2010). While each of these have disciplinary issues that can present themselves, each also needs to have techniques in which to deal with misbehavior.

In imitative learning, or a child copying someone, problems can arise by what they have seen peers do, but more over what they see adults do. Children see many things that occur in everyday life that many of us would ignore. However, most children will take notice and then they have a more likely chance of repeating what they have seen. Though a parent or teacher monitors what their children see, they also need to be able to discuss events before any misbehavior may become an issue. This becomes increasingly true with what children hear. It is difficult to censor what a child hears. Teachers will always have students that say inappropriate comments in class because they do not know what it means. In this instance a teacher needs to be open to discussing with the student why what they have said is bad. The teacher also needs to have open communication with the parents. This is not to increase punishment on the child, but to simply inform them of what has been said in the classroom. The more parents are able to monitor what their children see and hear at home, the less likely the issue will present itself in the classroom.

Instructed and collaborative learning are similar as they each are a more structured and directed form of learning. In these areas of the theory children are shown lesson, work and understanding. Disciplinary techniques in this area would need to be more strongly focused on the group rather than each specific child. As open discussion and group activities persist in the classroom, the teacher will need to monitor the behavior of the children, primarily around peers.

\section{Conclusion and Recommendations for Future Research}

Vygotsky's Social Development Theory is continually applicable even as elements of learning, distraction, and education styles evolve. Even more important is the aspects of the theory that have to do with interactive learning. Communication and interactivity between children and their peer groups, educators and adults are all critical components to developmental learning. This means that increased distraction can limit the necessary developmental outcome of the child. A child has a heightened reception to their environment and gain influence from that environment regardless of parent or teacher intervention. This means that as the child develops, careful monitoring of surroundings is important. When applying these principles in the classroom, communication is the central theme. This means that while learning functions change and techniques evolve, communication remains the cornerstone of cognitive learning.

Future researchers will want to evaluate the communication mechanisms that change more rapidly than the theory itself. As the means of communication change, this impacts social development and how we must educate.

\section{References}

Bee, H., \& Boyd, D. (2007). The Developing Child (11th ed.). Upper Saddle River, NJ: Allyn \& Bacon.

Cody, K. \& Powell, K.Constructivism, Teaching Methods, Cognitive models. Education. Chula Vista:Winter 2009.

Vol. 130, Iss. 2 pg. 241, 10pgs

Garrison, C., \& Ehringhaus, M. (2007). Formative and summative assessments in the classroom.

Huitt, W., \& Hummel, J. (2003). Piget's Theory of Cognitive Development. Educational Psychology Interactive. Kids Development. (2010). Vygotsky and Social-Cultural Theory. Retrieved from http://www.kidsdevelopment.co.uk/VygotskySocioCulturalTheory.html

Simpson-Beck, V. (2011). Assessing Classroom Assessment Techniques, 12(2), 125-132.

Retrieved from https://journals.sagepub.com/doi/abs/10.1177/1469787411402482

Zone of Proximal Development. (2006). In Encyclopedia of Special Education: A Reference for the Education of the Handicapped and Other Exceptional Children and Adults. Retrieved from http://www.credoreference.com/entry/wileyse/zone of proximal development

L. Seth Barnett: Seth Barnett is considered an expert on cooperative marketplace success. He regularly speaks around the world to professionals in various industries about how to engage with and adapt to changing markets 
and has presented many new theories on human behavior. He has appeared in numerous publications on this topic in periodicals across the US and the UK as well as several top academic journals. Seth has been a guest instructor at Texas Christian University, Boise State University, the Florida Institute of Technology, the College of Western Idaho, and Johnson \& Wales University. He holds a bachelor of science degree in Management from Johnson \& Wales University, a master's degree in Public Administration from Walden University, a master's degree in Law from American Public University, and is earning a doctorate in Organization Development from Johnson \& Wales University where his research focuses on the theory of cultural dimension in organizational evolution. Seth currently serves as the Vice President of Strategic Partnerships for AIM Smarter, LLC, the largest membershipbased marketing distributor company in the U.S. Seth is based in Philadelphia and resides in Fort Worth, Texas. 